\title{
Identifying functional regions in Australia using hierarchical aggregation techniques
}

\author{
William Mitchell, Anthea Bill and Martin Watts ${ }^{1}$ \\ Centre of Full Employment and Equity \\ The University of Newcastle
}

\begin{abstract}
This paper continues our work focused on developing a new socioeconomic geography for Australia such that the chosen spatial aggregation of data is based on an analysis of economic behaviour. The underlying hypothesis is that the development of a geographical classification based on underlying economic behaviour will provide new insights into critical issues of regional performance, including unemployment differentials, the impact of industry, infrastructure and changes in local public expenditure on local labour markets. As a precursor to detailed work on the 2006 Census data, we establish the proof of concept in this paper of the Intramax methodology using 2001 ABS Journey-to-Work data for NSW. The functional regionalisation generated by the Intramax method is then tested using ABS labour force data. We compare 2001 ABS Census data aggregated by the ABS labour force regions to the same data aggregated using our functional regions. The results demonstrate the potential value of this technique for the development of a new geography.
\end{abstract}

\section{Introduction}

This paper continues our work focused on developing a new socio-economic geography for Australia such that the chosen spatial aggregation of data is based on an analysis of economic behaviour. The underlying hypothesis that has motivated this work is that the development of a geographical classification based on underlying economic behaviour will provide new insights into critical issues of regional performance, including unemployment differentials, the impact of industry, infrastructure and changes in local public expenditure on local labour markets. A systematic understanding of level of interaction between neighbouring regions, will facilitate an assessment of the adequacy of the administrative geographical demarcations currently used by the Australian Bureau of Statistics (ABS) to collect and disseminate their labour force data.

Recent Australian studies have analysed spatial patterns of unemployment, housing and related socio-economic phenomena using administratively-defined Australian Standard Geographical Classification (ASGC) spatial aggregations typically at the Statistical Local Area (SLA) and/or Statistical Region (SR) level (for example, O'Connor and Healy, 2002; Lawson and Dwyer, 2002; Baum et al., 2005; Mitchell and Carlson, 2005; Yates, 2005; Yates et al., 2006a, 2006b; Mitchell and Bill, 2006, Gregory and Hunter, 1995). Most Australian researchers are reluctant to acknowledge that the interpretation of these spatial data can be compromised by the Modifiable Areal Unit Problem (MAUP), although this problem has long been recognised by geographers. Openshaw (1984:3) says that "the areal units (zonal objects) used in many geographical studies are arbitrary, modifiable, and subject to the whims and fancies of whoever is doing, or did, the aggregating" and resulting analyses are 
fraught. In short, chosen spatial groupings must be justified and these aggregations are modifiable.

Just as geographical regions may be defined by physical features, we hypothesise that a meaningful socio-economic geography should be defined by socio-economic features of space. It is most unlikely that that these "regions" will correspond exactly to a demarcation based on administrative/political criteria. Significant issues arise when erroneous geography is used. First, a poorly delineated geography invokes measurement error. Thus, a local measure such as SLA unemployment, may be unrelated to socio-demographic and policy variables at a similar scale, and lead to spurious causality being detected and misguided policy conclusions. Second, analysing erroneously aggregated spatial data with standard statistical tools will yield results that may not only lack economic meaning but also suffer bias due to spatial correlation. Our conjecture, based on an earlier pilot study (Watts, Baum, Mitchell and Bill (WBMB), 2006), is that studies relying on ABS administratively-based Census areas, or LF regions devised for the dissemination of the Labour Force Survey, produce misleading inferences when applied to socio-economic analysis or policy. WBMB (2006) found significant spatial correlation in key labour market variables and sensitivity to spatial aggregation, when they compared AGSC geography with experimental commuting areas generated using the 2001 Census data.

Unfortunately, only limited attempts have been made in Australia to create such a 'space' (see WBMB, 2006). Journey-to-work (JTW) data provides information about the interaction between a large number of spatial units and is a useful basis for defining a functional regionalisation. The theoretical basis for demarcating regions based on commuting behaviour is outlined in WBMB (2006). It is applicable to any of the possible aggregation methodologies that are available. A commuting area is conceived as a geographical area within which there is a high degree of interactivity (commuting by residents) and is thus the appropriate spatial scale to capture the interplay between labour supply and demand in a particular localised setting. These spatial markets result from both costs of mobility between jobs and the limitations of information networks (Hasluck, 1983). Employers and workers that interact within a functional area are assumed to be well informed and able to respond quickly to changes in market conditions relative to those outside any particular area. While Hasluck (1983) is critical of such attempt to create such regionalisations; on balance, we support Green (1997) who sees commuting clusters as revealing the boundaries of local labour demand and supply and hence a sound basis for an 'an alternative geography' for labour market analysis.

Different terminology has been employed to identify these areas including Commuting Area, Local Labour Market Areas, Functional Labour Market Areas and Commuting Zones. Early on, Berry (1968) referred to these aggregations as functional regions. In this paper and consistent with the extant literature (on intramax techniques) we use functional areas to describe our regional aggregations based on JTW data. In this paper, and consistent with our conjecture above, we seek alternative aggregations of the JTW data which reflects economic behaviour (commuting interaction) rather than administrative structures.

Previous work by Watts (2004) and WBMB (2006) used a non-hierarchical, rules-based demarcation method first developed by Coombes et al (1986) to determine a new 'behavioural-based' geography (for a description of the method see Coombes et al, 1986: 948-52 and Papps and Newell, 2002: 9-14). Appendix Figure A1 presents the mapping for New South Wales (NSW) derived from Watts (2004). Spatial autocorrelation measures were calculated using unemployment rates at the postal area level in 2001, to examine the regions generated by Watts (2004), termed 'commuting areas' or local labour markets (LLMs). 
Global spatial autocorrelation indices are formal measures of the extent to which near and distant things are related. Global statistics can be decomposed to provide local measures of spatial association (LISAs), which reveal statistically significant clusters of above average values (hotspots) and statistically significant below average concentrations (coldspots) for the phenomena under investigation. LISA maps at the postal area level revealed considerable spatial heterogeneity in LF outcomes, and highlighted a key motivation for the development of the new geography. They revealed that Statistical Region (SR) boundaries which roughly approximate ABS LF geography conflate areas with statistically significant heterogeneity (that is both hotspots and coldspots), while finer commuting areas generally did not. However as the Sydney 'commuting area' comprised the entire Sydney Metropolitan Area (see Figure 1) the 'commuting area' geography seem to miss much of the significant (non-random) heterogeneity in LM outcomes within Sydney. Notably it created a geography which conflated unusually low and statistically significant clustering of unemployment rates in the eastern and northern suburbs and clusters of unusually high unemployment rates in Sydney's inner and outer west. ${ }^{2}$

In this paper we take an alternative approach to functional regionalisation and deploy the Intramax method. JTW flows between areas can be depicted as a square matrix with each row denoting an origin (residential location) and each column representing a destination (workplace location) (see Table 1). The Intramax method is a hierarchical clustering algorithm (Masser and Brown, 1975) that maximises 'the proportion of the total interaction which takes place within the aggregation of basic data units that form the diagonal elements of the matrix, and thereby to minimise the proportion of cross-boundary movements in the system as a whole' (Masser and Brown, 1975: 510). Masser and Scheurwater (1980: 1361) say that the 'intramax procedure is concerned with the relative strength of interactions once the effect of variations in the size of the row and column totals is removed ... relative strength is expressed in terms of the difference between the observed values and the values that would be expected on the basis of the multiplication of the row and column totals alone.'

The Intramax method is concerned with how the aggregation impacts on interaction flows (journeys) across the regional boundaries. Looking at Table 1, the main diagonal elements of the JTW (at any stage of aggregation) capture the journeys that begin and end in the same region, whereas the off-diagonal elements show journeys that cross regional borders. Masser and Brown (1975: 509) say that 'the most important distinction that must be made in the grouping procedure is between the proportion of interaction in the diagonal as against the nondiagonal elements of the basic flows matrix' (emphasis in original).

Barros et al. (1971: 140) refers to the 'strength of interaction' as the proportion of total journeys that cross regional boundaries. Clearly, as we aggregate smaller regions into larger functional areas, the proportion of interaction that cross boundaries should decline and a rising proportion of interactions thus would be considered intra-regional.

As a way forward, we seek to define our functional economic areas, by aiming to 'maximise the proportion of the total interaction which takes place within the aggregations of basic data units that form the diagonal elements of the matrix, and thereby to minimise the proportion of cross-boundary movements in the system as a whole' (Masser and Brown, 1975: 510).

Results reveal the Intramax technique to be a very useful for understanding the operation of the Sydney labour market and demarcating commuting areas. At each stage of the clustering process fusion occurs between regions in such a way as to maximise commuting flows or interaction - providing valuable insight into those SLAs whose labour markets are most 'linked' in metropolitan and non-metropolitan NSW. Overall the technique collapses many of the standard labour force regions (used by the ABS in the dissemination of its statistics) in 
metropolitan Sydney (but preserves established distinctions between east and west) and splits many non-metropolitan LF regions, particularly around major regional centres. An application to 2001 Census data reveals that on average regional unemployment rates are higher and labour force participation rates are lower when applying this new geography, which minimises intra-region dispersion (measured by the standard deviation in unemployment rates). The paper is organised as follows. Section 2 describes the data used in this study. Section 3 outlines the Intramax method to functional area demarcation. Section 4 presents the regionalisation based on the application of the Intramax method and analyses some of the implications of the resulting geography. Concluding remarks follow.

\section{Data}

Australian Bureau of Statistics 2001 Census Journey to Work data was used at the Statistical Local-Area (SLA) level for-NSW and its cross border interactions (the area chosen to allow a direct comparison with Watts, 2004 which used the Coombes approach). ${ }^{3}$ Using the 2001 JTW datacube from the ABS Census, we deleted the following destination locations (columns): Sydney (undefined); no fixed address; migratory and off-shore; and undefined NSW; not stated and not applicable. Lord Howe Island was also deleted. In addition, the corresponding residential (origin) locations were deleted (rows). The remaining JTW matrix thus had 197 SLAs. To protect confidentiality small flows are randomised by the ABS. Consequently all entries of less than 6 were set to zero.

To help in the explication of the Intramax technique, Table 1 provides a schematic representation of the square JTW flow matrix where the rows are designated as origins and the columns are destinations. 
Table 1 JTW flow matrix with $j$ regions

\begin{tabular}{|c|c|c|c|c|c|}
\hline Destination & Region 1 & Region 2 & $\cdots$ & Region $j$ & Total \\
\hline Origin & 1 to 1 & 1 to 2 & $\cdots$ & 1 to $j$ & $\sum_{j} a_{1 j}$ \\
\hline Region 1 & 2 to 1 & 2 to 2 & $\cdots$ & 2 to $j$ & $\begin{array}{c}\text { Sum of flows out } \\
\text { of Region } 1\end{array}$ \\
\hline Region 2 & $\ldots$ & $\ldots$ & $\cdots$ & $\ldots$ & $\sum_{j} a_{2 j}$ \\
\hline Region $j$ & $j$ to 1 & $j$ to 2 & $\cdots$ & $j$ to $j$ & $\ldots$ \\
\hline Total & $\begin{array}{c}\sum_{i} a_{i 1} \\
\text { Sum of flows } \\
\text { into Region } 1\end{array}$ & $\sum_{i} a_{i 2}$ & $\cdots$ & $\sum_{i} a_{i j}$ & \begin{tabular}{c}
$\sum_{j} a_{j j}$ \\
\hline
\end{tabular} \\
\hline
\end{tabular}

The summary details of the $197 \times 197$ matrix for NSW journey-to-work flows between SLAs are detailed in Table 2. Zero elements constitute 88 per cent of the JTW matrix (no commuting between pairs of places) which means that the 'network depicting the commuting patterns is relatively unconnected' (Brown and Holmes, 1971: 61).

Table 2 Summary characteristics of JTW matrix, NSW, 2001.

Number of regions

Percentage of zero elements in JTW matrix (\%)

Total interaction (trips)

Intra-regional interaction (trips) - Trace of matrix

Percentage of intra-regional trips (\%)

\section{The Intramax method}

\subsection{The Intramax technique}

The Intramax method considers the size of the interaction (ITW flows) to be 'of fundamental importance' (Masser and Brown, 1975: 510). To express this concern the method considers the 'interaction matrix', that is, the JTW matrix to be a 'form of contingency table' and then formulates the 'objective function in terms of the differences between the observed and the expected probabilities that are associated with these marginal totals' (Masser and Brown, 1975: 510).

If we view Table 1 as a contingency table then the expected values of each element are derived as the product of the relevant column sum (Equation 3) times the ratio of the row sum (Equation (2) to total interaction (Equation 4). For example, the expected flow out of Region 
2 into Region $1, \mathrm{a}(2,1)$ in Table 1 , where $a_{\mathrm{ij}}$ is the element in row $i$ and column $j$ of the contingency table (JTW matrix), is given as

$$
a_{21}^{*}=\sum_{i} a_{i 1} \frac{\sum_{j} a_{2 j}}{\sum_{i} \sum_{j} a_{i j}}=\sum_{i} a_{i 1}\left(\sum_{j} a_{2 j} / n\right)
$$

This is the 'flow that would have been expected simply on the basis of the size of the row and column marginal totals' (Masser and Brown, 1975: 512).

The row sum of the JTW matrix is

$$
a_{i^{*}}=\sum_{j} a_{i j}
$$

The column sum of the JTW matrix is

$$
a_{j^{*}}=\sum_{i} a_{i j}
$$

The total interaction $n$ is the sum of the row sums

$$
n=\sum_{i} \sum_{j} a_{i j}
$$

The null hypothesis for independent between the row and column marginal totals of a contingency table is defined as:

$$
H_{o}: a_{i j}^{*}=\frac{\sum_{j} a_{i j} \sum_{i} a_{i j}}{n}=\frac{a_{i^{*}} a_{j^{*}}}{n}
$$

If the grand total of the flows is normalised such that $n=1$ and $a_{i j}^{*}=a_{i^{*}} a_{*_{j}}$ then Masser and Brown (1975: 512) note that 'the difference between observed and expected values $\left(a_{i j}-a_{i j}^{*}\right)$ for the flow between zone $i$ and zone $j$ may be taken as a measure of the extent to which the observed flow exceeds (or falls below) the flow that would have been expected simply on the basis of the size of the row and column marginal totals.'

In these circumstances, the objective function of the hierarchical clustering algorithm using a non-symmetrical JTW matrix is defined as

$$
\max I=\left(a_{i j}-a_{i j}^{*}\right)+\left(a_{j i}-a_{j i}^{*}\right), \quad i \neq j
$$

Masser and Brown (1975) place a contiguity constraint on the maximisation process to eliminate the possibility that clusters between non-contiguous regions would form. In terms of the Intramax procedure, there is very little chance that contiguity would not be satisfied in the clustering process. As intra-zonal flow increases (at higher levels of the dissolution process) the newly forming clusters are almost certain to be contiguous. However, in terms of the commuting application there is no logical reason why two non-contiguous regions could not belong to the same local labour market. Peculiarities of the housing, occupational and transport patterns overlaying employability could generate such a result. In our data, the contiguity constraint is not enforced but the results deliver clusters where all sub-regions in the functional areas are contiguous. 


\section{Results}

There were 4633 iterations in the Intramax process. ${ }^{4}$ At each stage of the clustering process, fusion occurs such that the regions have the strongest possible commuting ties (interaction). The stepwise procedure then combines the clustered interaction and the matrix is reduced by a column and a row. With $N$ regions (197 in our study) after $N-1$ (196) steps, all regions are clustered into a single area (the state of NSW) and by construction, all interaction is intrazonal (one matrix element remaining). Regions with large JTW flows are fused in the first stages of the process and those with small gross intra-region JTW flows are fused in the later stages of the clustering process. The results for NSW as a whole are shown in the form of a dendrogram (Figure A2) which spans six pages. Figure 1 produces a dendrogram for the Sydney MSR (excluding the Hunter) (spanning 1.5 pages) and Figure 2 produces a dendrogram for the Gosford-Hunter region.

Recall from the previous work of WBMB (2006) that the Coombes methodology, while yielding significant aggregations of SLAs, did not generate fine spatial demarcations of functional economic areas within the Sydney MSR. In this context, Figures 1 and 2 reveal some very interesting patterns. In the first stages of the aggregation process Burwood and Strathfield fuse to form the basis of an inner-west Sydney functional area with Ashfield, Concord, Drummoyne (all of which are in the Inner Western Sydney Statistical Subdivision in the ASGC) and then collect Leichardt soon after. Around 58 per cent of all the JTW flows in and out of these regions are intra-zonal for this new aggregation. Canterbury and Marrickville also fuse early and incorporate Bankstown soon after to form an inner southwest Sydney functional area. Around 55 per cent of the JTW flows in and out of these regions are intra-zonal. Figure 3 to 6 map the subsequent clustering whereby the inner west and inner south-west fuse to form a new functional area and around 65 per cent of its total flows are intra-zonal.

To the south and east of the Sydney CBD, other functional areas form. Botany Bay initially fuses with Randwick and Waverley with Woollahara. At this point intra-zonal flows in each constitute around 48 per cent of total flows. The two sub-regions fuse (52 per cent intrazonal) then fuse with South Sydney. In turn, this grouping fuses with Sydney CBD (SydneyInner and Sydney Remainder) and the new aggregation has around 65 per cent intra-zonal interaction. At a later stage of the grouping this entire block forms a new cluster and the proportion of intra-zonal JTW flows are around 78 per cent for this new group. There are still cross-boundary flows ( 22 per cent) but there is strong sense of intra-action in this grouping.

To the south-west, Kogarah and Hurstville fuse first as do Sutherland Shire-East and Sutherland Shire-West. Rockdale joins the first of these clusters and together they fuse with the Sutherland Shire cluster to form a 5 SLA functional area, quite distinct from the-near inner south-west and inner-west and south and east clusters discussed above. This larger southern cluster has around 57 per cent of its total flows as intra-zonal. Figure X maps this level of regional demarcation. At a much later stage of the aggregation the southern cluster fuses with the previous cluster incorporating Sydney CBD, inner west and inner south-west and inner south and east to form a cluster where 80 per cent of the total flows are intra-zonal.

In the north, Hornsby looks east to Ku-ring-ai and to the north-east Hunter's Hill and Ryde fuse (both clusters containing 50 per cent intra-zonal flows). These north and north-east clusters in turn fuse with about 60 per cent of their flows intra-zonal. Closer to Sydney on the north side, Lane Cove and Willoughby fuse as do Mosman and North Sydney (again with about 50 per cent of their total flows being intra-zonal). These cluster fuse and then fuse again with the north-east and northern cluster with about 60 per cent of their flows being intra-zonal. 
Figure 1 Dendrogram for Sydney-Illawarra

\begin{tabular}{|c|c|}
\hline 105350150 & Asheield \\
\hline 105351300 & Eurwood \\
\hline 105357100 & Strath \\
\hline 105351900 & concord \\
\hline 105352550 & Drumusyne \\
\hline 105054800 & Letchtardt \\
\hline 105200350 & Bankstow \\
\hline 10501550 & Canterbury \\
\hline 105055200 & Marrickvile \\
\hline 105051100 & Bozany Bay \\
\hline 105106550 & Randwick \\
\hline 105108050 & Wayeniey \\
\hline 105100500 & Woollahra \\
\hline 105057070 & South Syaney \\
\hline 105057201 & Syaney-Innex \\
\hline 105057202 & Sydney-Remainder \\
\hline 105154150 & Hurstville \\
\hline 105154550 & Jogarah \\
\hline 185156650 & Rochdale. \\
\hline 105157151 & Sutheriand shire-East \\
\hline 105157152 & Sutherland shire-west \\
\hline 105604000 & Hornsty \\
\hline 105604500 & Wu-ring-gai \\
\hline 105554120 & hunter's Bill \\
\hline 105556700 & Ryde \\
\hline 105554700 & Iane Cove \\
\hline 105558250 & Finloughby \\
\hline 105555350 & Mosman \\
\hline 105555050 & North Sychey \\
\hline 105655150 & $\operatorname{ManI}$ \\
\hline 105658000 & Warringen \\
\hline 105656370 & Fitswater \\
\hline 105400200 & Auburn \\
\hline 105403950 & Bosroy \\
\hline 105406250 & Earrametea \\
\hline 105600500 & Baulhnas Hisls \\
\hline 5530751 & Elachown-Hor \\
\hline
\end{tabular}






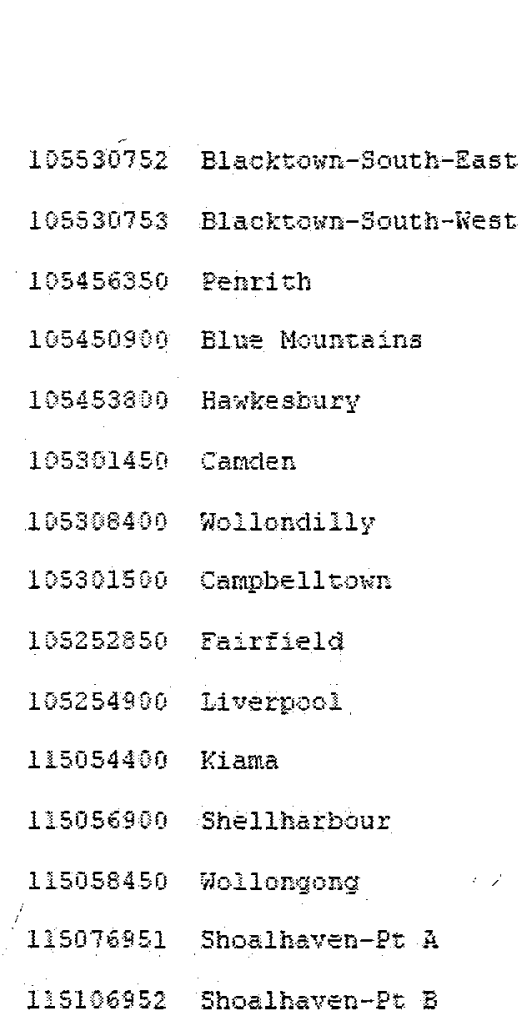

per cent of intra-zonal flows

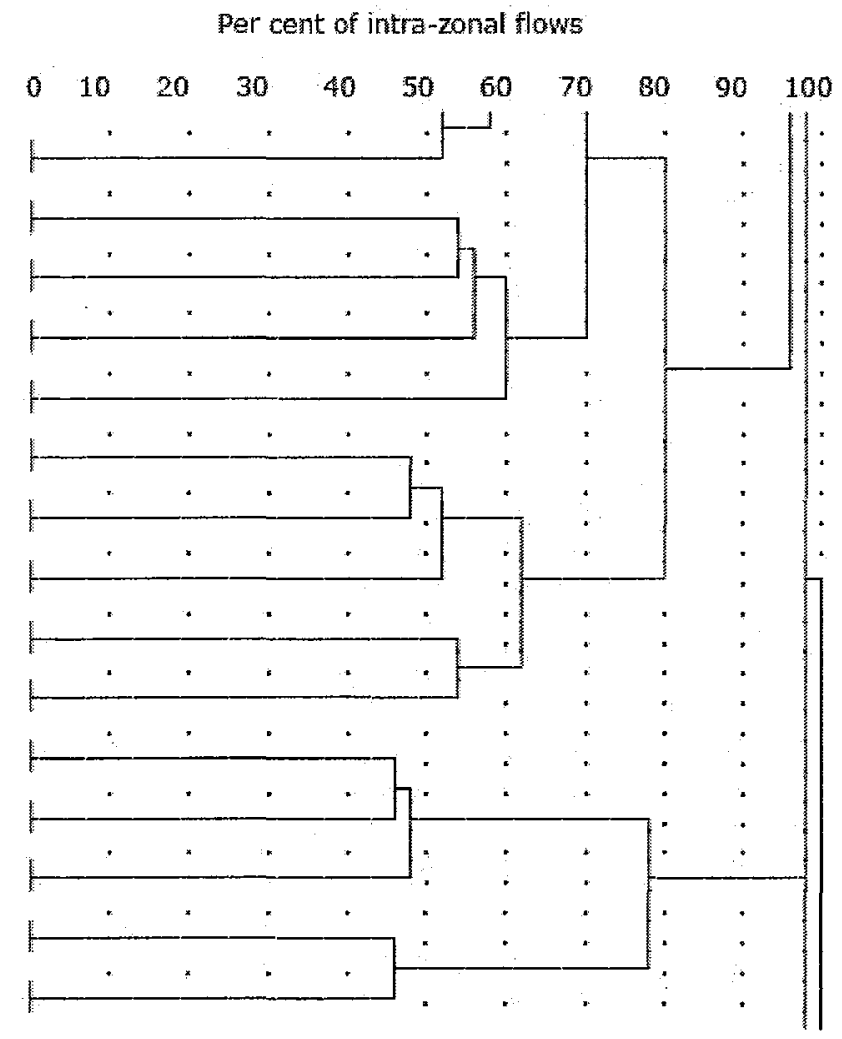

Interestingly, nearby north-side regions Manly and Warringah (east of the Pacific Highway) fuse early and then attract Pittwater which is further north along the coast. Together this new cluster of 3 northern coastal SLAs represents a definable cluster containing about 50 per cent of intra-zonal flows. They subsequently fuse with the other north/north-east cluster where about 60 per cent of total flows are intra-zonal.

At a later stage of the clustering process the north/north-west regions fuse with cluster south/south-west/east including the Sydney CBD to form a larger functional area where the proportion of intra-zonal flows exceeds 80 per cent. This is a strongly defined cluster.

A further interesting point is that the SLAs in the outer western parts of the Sydney MSR Holroyd and Parramatta fuse and then look south to fuse with Auburn. Similarly, BlacktownNorth and Blacktown-South fuse first then look north-east and fuse with Baulkham Hills. These two larger clusters in turn aggregate and the percentage of intra-zonal flows to total flows for this new cluster exceeds 55 per cent.

Nearby, Blacktown-South West looks further to the west and fuses with Penrith and this cluster fuses further to the west with the Blue Mountains and to the north with Hawkesbury. The new cluster has about 55 per cent of its total flows as intra-zonal. This northwestern/western cluster aggregates into the Holroyd/Parramatta/Blacktown-North and South and Baulkham hills cluster with 65 per cent of intra-zonal flows.

Further to the south-west, Camden and Wollondilly fuse, then fuse with Campbelltown. Liverpool and Fairfield also fuse. These two south-western clusters aggregate to form a welldefined south-west functional area with about 55 per cent intra-zonal flows.

In turn, at the next significant grouping stage this south-west grouping aggregates with the north-west/outer-west cluster to form a strongly defined grouping in outer Sydney and the percent of total flows that are intra-zonal is about 70 per cent. 
When this south-west cluster eventually aggregates with the other large Sydney cluster some 90 per cent of total flows for this large region are intra-zonal.

The Illawarra SLAs are quite distinct. Kiama and Shellharbour fuse as do Shoalhaven-Part A and Shoalhaven-Part B. The Kiama/Shellharbour cluster fuses with Wollongong and then with the Shoalhaven pair. At this level of aggregation, intra-zonal flows constitute about 70 per cent of total flows for this Illawarra region. This region clusters with the large Sydney region at around 92 per cent intra-zonal, and just after the big outer west/south-west cluster fuses with the larger Sydney cluster.

Of interest is the way in which Wingecarribee (part of the Illawarra Statistical Division) stands separate with around 78 per cent of its total flows being intra-zonal and looks further south into the rural areas of Boorowa, Gunning, Yass, Queanbeyan, and the ACT to form a larger cluster.

Figure 2 Dendrogram for Central coast and Hunter functional regions

per cent of intra-zonal flows

\begin{tabular}{|c|c|}
\hline 105703100 & Gostord \\
\hline 105708550 & Wrong \\
\hline 130051720 & Cessnock \\
\hline 110107000 & $\operatorname{singleton}$ \\
\hline 130102790 & Dungog \\
\hline 130055050 & Maitiand \\
\hline 130056490 & Eort steplens \\
\hline 130054650 & Lake Hacquarie \\
\hline 120055901 & Nenosgste-Inner \\
\hline 120055902 & Newcastle-Remainder \\
\hline 120105650 & Musweilbrook \\
\hline 130186800 & Scone \\
\hline
\end{tabular}

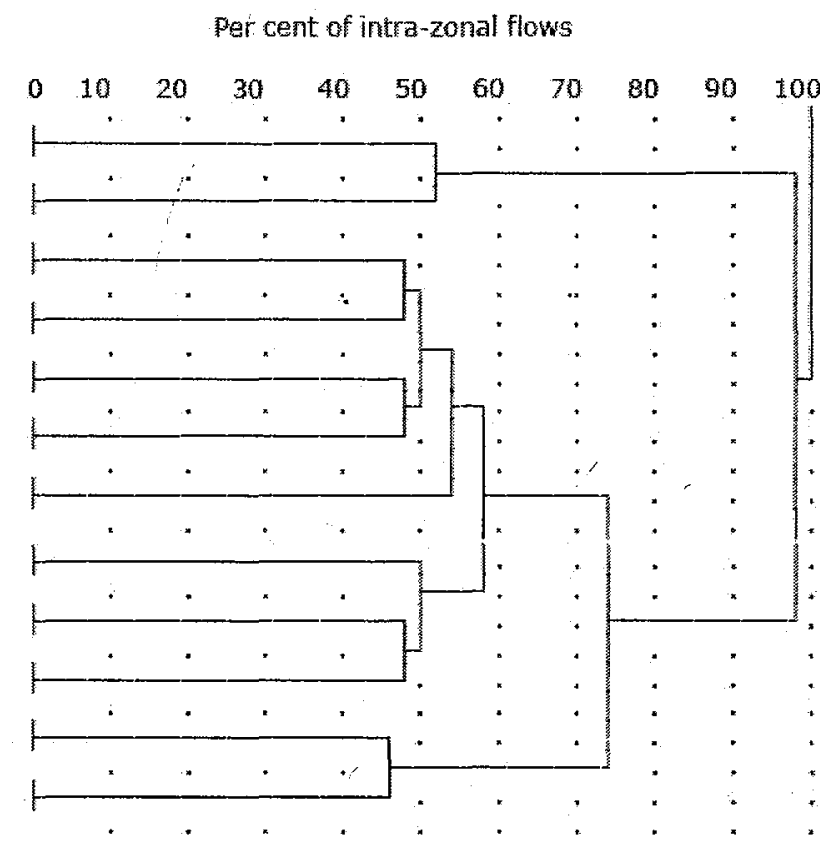

Another interesting result is the Gosford and Hunter region SLAs (see Figure 2). Gosford is typically considered to be part of the Sydney metropolitan area (WBMB, 2006) but these results challenge that assertion. Gosford initially fuses with Wyong to the north (to make a region with 52 per cent of total flows intra-zonal). Cessnock and Singleton fuse as do Dungog and Maitland and these two clusters fuse to form a new grouping (with 50 per cent of its total flows intra-zonal). Port Stephens looks west to this cluster first. Newcastle Inner and Newcastle remainder fuse first then look south to fuse with Lake Macquarie. This aggregation then fuses with the lower Hunter cluster (including Port Stephens). This new functional region has about 58 per cent of its total flows intra-zonal). Upper Hunter SLAs Muswellbrook and Scone fuse (48 per cent intra-zonal) and fuse with the lower Hunter/Lake Macquarie cluster (74 per cent intra-zonal).

The upper Hunter SLA of Gloucester looks north to the fusion between Taree and Great Lakes and these in turn form a mid-north coast/hinterland cluster with Hastings, Kempsey and Nambucca ( 88 per cent intra-zonal). They further aggregate north rather than south.

These results clearly indicate that Gosford looks northwards rather than southwards in terms of dominant commuting interaction. 
To render the concept of functional areas operational some level of clustering (number of steps) has to be chosen and the resulting regionalisation defined. The exact point where we stop is judgemental and cannot be determined in any rigid way. Clearly some maximum level of commuting is one way in which we can draw the line. Other authors have defined the "stop criterion" as some level of clustering (number of steps) where homogeneity within a cluster is lost (Goetgeluk, 2006). Goetgeluk (2006: 11) says that a large increase in the intra-zonal flows during the fusion process does not generally indicate 'a merger of two rather homogenous zones.' The "stop criterion" would thus use the regionalisation that was defined 'just before the high increase in intra-zonal flows' (Goetgeluk, 2006: 11).

We can determine this point from an examination of the dendrogram (FigureA1) and the Fusion report (summarised in Table 3) provided by the Intramax process. Prior to the start of the fusion process, Table 2 tells us that the total number of intra-zonal flows is $1,099,613$ representing 44.9 per cent of all the inter-regional flows (trips). Table 3 presents truncated version of the Fusion report for the Intramax process starting at Step 69 (which involved the fusion of the two Newcastle SLAs and was the first significant jump in the cumulative intrazonal interaction). The large jumps or "break points" in the Fusion output occur when there are significant increases in the cumulative intra-zonal interaction as a result of a fusion. These start occurring from Step 168, then Steps 170, 174, 176 and 182. In terms of Steps 168 and 170 these involve the inner west clustering with the inner south (168) and then the Sutherland Shire clustering with the inner south (170). Further analysis is required to determine whether these pre-clustered regional aggregations are interactive enough to be classified as functional areas in their own right. We suspect not at this stage and as a consequence we considered Step 173 to be a reasonable stop point such that 78 per cent of flows were now considered intra-zonal by this regionalisation and 24 regions emerge as distinct functional areas. In making this decision, we decided that the fusion determined by Step 174 (outer south-west with west) wás creating an aggregation that probably blurred important labour market differences. This is pure conjecture at this stage and further analysis is required of occupation and industry data to test its veracity.

We identified 3 useful regionalisations that will provide the basis of further analysis and testing. Cluster 2 (24 regions and 78 per cent cumulative intra-zonal flows), which is our preferred stop point in this paper, is the intermediate level. Cluster 1 defined 40 functional areas with cumulative intra-zonal flows of 63.28 per cent, whereas Cluster 3 defined 15 regions with cumulative intra-zonal flows of 96.7 per cent.

The maps in Figures 3 to 6 compare the Functional Areas (Cluster 2) geography generated above with the standard ABS Labour Force geography (which roughly conform to Australian Standard Geographical Classification Statistical Regions), used to disseminate regional statistics from the Labour Force Survey (see ABS, 2004). ${ }^{5}$ In aggregate for NSW approximately the same number of regions exists in both geographies: 21 Labour Force regions and 24 Functional Areas (FAs). However the spatial distribution of these regions is significantly different between the two geographies.

Three general points can be made: (a) Many more regions are generated in non-metropolitan NSW when using the Functional Area (FA) geography, particularly in the north and northwest, compared to the standard LF geography; (b) Large regional towns (such as Wagga Wagga, Albany and Dubbo) emerge as epicentres of FAs; and (c) Fewer FA regions emerge in Sydney than currently exist in the standard ABS Labour Force geography. 
Other more specific comments include:

- The Functional Area (FA) geography divides Inner Sydney in two and combines Eastern Suburbs and Inner Sydney to form one Sydney eastern suburb Functional Area (see Figure 2 and 4);

- Canterbury Bankstown, Inner western Sydney and eastern Inner Sydney combine to form an inner-west FA;

- Fairfield Liverpool and outer South Western Sydney Statistical Regions (SRs) combine to form an outer South Western Sydney FA;

- Central Western Sydney SR, North Western Sydney SR, Central Northern Sydney SR (east side) combine to form one Western Sydney FA;

- Wollongong Statistical Region Sector and Nowra SR form one FA along the south coast;

- Part of Illawarra SR (excluding Wollongong) combines with Goulburn; Wingecarribee combines with South Eastern SR to form one geography;

- Newcastle statistical region sector and Hunter combine to form one FA;

- The Hunter SR divides at Gloucester/Great Lakés to combine with Port Macquarie to form a mid-north coast FA (running up to Nambucca);

- An FA emerges in Dubbo and surrounds (formerly part of the Northern, Far-West North Western SR), also incorporating Merriwa, formerly in the Hunter SR;

- Orange and Bathurst and surrounds (part of the Central West SR) form one FA;

- Murray-Murrumbidgee SR splits into four separate FAs: one situated in the far north west in Wentworth and surrounds; one encompassing Hay and the Murray Murumbidgee region; one situated in and around Albany and one in Wagga Wagga and surrounds;

- The Far West North Western SR is broken into 8 Functional Areas. Tenterfield combines with Richmond Tweed (Lismore) SR to form one FA; an FA emerges around Armidale and one around the Tamworth, as well as separate FAs encompassing Dubbo and Broken Hill, and their surrounds. In the south east of the Central West SR an FA emerges around Bathurst. Cobar (Far West North West) combines with Lachlan, Parkes, Bland Forbes, Bland, Forbes and Weddin all regions formerly in the Central West SR to form one FA. Finally part of the Northern SR forms one FA encompassing towns of Walgett, Narrabri, Moree Plains, Bingara and Yallaroi.

- Murrurundi (formerly part of the Hunter SR), merges with part of the Northern Far-North Western (encompassing Manilla, Barraba and Gunnedah) to form an FA;

- The SR of Richmond Tweed and Mid North Coast separate to form 3 geographies. One FA situated around Lismore and surrounds (combining with Tenterfield as mentioned), another encompassing Coffs Harbour and surrounds and a third centred on Port Macquarie (and combining with Gloucester/Great Lakes in the south, formerly part of the Hunter SR). 
Table 3 Fusion report for the Intramax aggregation process, NSW SLAs 2001

\begin{tabular}{|c|c|c|c|c|c|c|}
\hline Step & Dissolved Area & & Enlarged Area & $\begin{array}{l}\text { Percentage } \\
\text { Intrazonal } \\
\text { Interaction }\end{array}$ & $\begin{array}{l}\text { Cumulative } \\
\text { Intrazonal } \\
\text { Interaction }\end{array}$ & $\begin{array}{l}\text { No of } \\
\text { Regions }\end{array}$ \\
\hline 0 & & & & 44.89 & 44.89 & 197 \\
\hline 69 & Newcastle-Inner & $\rightarrow$ & Newcastle-Remainder & $0.34 \%$ & $47.42 \%$ & 128 \\
\hline 87 & Shellharbour & $\rightarrow$ & Wollongong & $0.66 \%$ & $48.47 \%$ & 110 \\
\hline 92 & Lake Macquarie & $\rightarrow$ & Newcastle-Remainder & $1.25 \%$ & $50.29 \%$ & 105 \\
\hline 93 & Sutherland Shire-West & $\rightarrow$ & Sutherland Shire-East & $0.46 \%$ & $50.75 \%$ & 104 \\
\hline 101 & Wyong & $\rightarrow$ & Gosford & $0.54 \%$ & $51.95 \%$ & 96 \\
\hline 105 & Pittwater & $\rightarrow$ & Warringah & $0.37 \%$ & $52.38 \%$ & 92 \\
\hline 106 & Camden & $\rightarrow$ & Campbelltown & $0.34 \%$ & $52.72 \%$ & 91 \\
\hline 122 & Blacktown South-West & $\rightarrow$ & Penrith & $0.26 \%$ & $53.88 \%$ & 75 \\
\hline 127 & Liverpool & $->$ & Fairfield & $0.44 \%$ & $54.55 \%$ & 70 \\
\hline 133 & Holroyd & $\rightarrow$ & Parramatta & $0.37 \%$ & $55.24 \%$ & 64 \\
\hline 134 & Blue Mountains & $\rightarrow$ & Penrith & $0.31 \%$ & $55.54 \%$ & 63 \\
\hline 136 & Willoughby & $\rightarrow>$ & North Sydney & $0.43 \%$ & $56.23 \%$ & 61 \\
\hline 138 & Waverley & $\rightarrow$ & Randwick & $0.37 \%$ & $56.73 \%$ & 59 \\
\hline 140 & Cessnock & $\rightarrow$ & Newcastle-Remainder & $0.91 \%$ & $57.77 \%$ & 57 \\
\hline 141 & Hurstville & $\rightarrow$ & Sutherland Shire-East & $0.60 \%$ & $58.37 \%$ & 56 \\
\hline 142 & Baulkham Hills & $\rightarrow$ & Blacktown South-East & $0.39 \%$ & $58.76 \%$ & 55 \\
\hline 144 & South Sydney & $\rightarrow$ & Randwick & $0.87 \%$ & $59.65 \%$ & 53 \\
\hline 148 & Auburn & $\rightarrow$ & Parramatta & $0.27 \%$ & $60.14 \%$ & 49 \\
\hline 151 & Bankstown & $\rightarrow$ & Canterbury & $0.32 \%$ & $60.70 \%$ & 46 \\
\hline 152 & Campbelltown & $\rightarrow$ & Fairfield & $0.71 \%$ & $61.41 \%$ & 45 \\
\hline 154 & Blacktown South-East & $->$ & Parramatta & $1.46 \%$ & $62.88 \%$ & 43 \\
\hline 157 & Ryde & $\rightarrow$ & Hornsby & $0.39 \%$ & $63.28 \%$ & 40 \\
\hline 158 & Sydney-Inner & $\rightarrow$ & Randwíick & $1.89 \%$ & $65.17 \%$ & 39 \\
\hline 161 & North Sydney & $\rightarrow$ & Hornsby & $1.24 \%$ & $66.47 \%$ & 36 \\
\hline 163 & Penrith & $\rightarrow$ & Parramatta & $2.00 \%$ & $69.19 \%$ & 34 \\
\hline 165 & Warringah & $\rightarrow$ & Hornsby & $1.14 \%$ & $70.36 \%$ & 32 \\
\hline 168 & Canterbury & $\rightarrow$ & Randwick & $3.65 \%$ & $74.02 \%$ & 29 \\
\hline 170 & Sutherland Shire-East & $\rightarrow$ & Randwick & $3.82 \%$ & $77.91 \%$ & 27 \\
\hline 173 & Shoalhaven-Pt A & $\rightarrow$ & Wollongong & $0.07 \%$ & $78.03 \%$ & 24 \\
\hline 174 & Fairfield & $\rightarrow$ & Parramatta & $2.12 \%$ & $80.15 \%$ & 23 \\
\hline 176 & Hornsby & $\rightarrow$ & Randwick & $6.26 \%$ & $86.42 \%$ & 21 \\
\hline 182 & Parramatta & $\rightarrow$ & Randwick & $10.39 \%$ & $96.88 \%$ & 15 \\
\hline 183 & Gosford & $\rightarrow$ & Newcastle-Remainder & $0.27 \%$ & $97.16 \%$ & 14 \\
\hline 190 & Wollongong & $\rightarrow$ & Randwick & $0.94 \%$ & $98.23 \%$ & 7 \\
\hline 191 & Newcastle-Remainder & $\rightarrow$ & Randwick & $1.33 \%$ & $99.56 \%$ & 6 \\
\hline 195 & Hastings-Pt A & $\rightarrow$ & Randwick & $0.22 \%$ & $99.84 \%$ & 2 \\
\hline 196 & Orange & $->$ & Randwick & $0.16 \%$ & $100.00 \%$ & 1 \\
\hline
\end{tabular}

Source: ABS, JTW custom matrix, 2001. 
Figure 3 Comparison of ABS Labour Force Region geography and Functional Zone Geography (Cluster 2), NSW

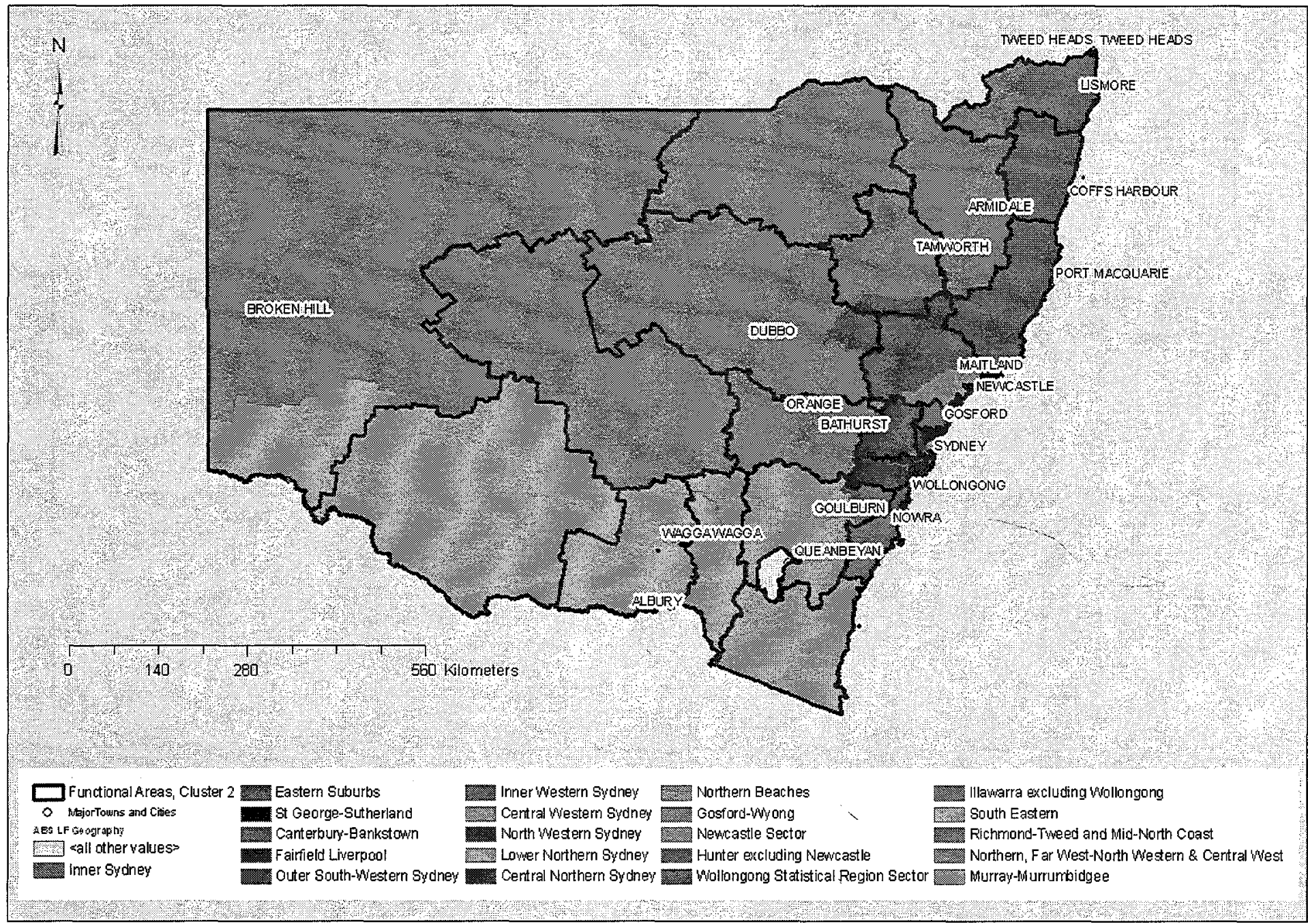

Source: ABS, JTW Custom matrix, 2001 and ABS, SLA to LF concordance 2004. 
Figure 4 Comparison of ABS Labour Force Region geography and Functional Zone Geography (Cluster 2), Sydney Metropolitan Region



Source: ABS, JTW Custom Matrix, 2001 and ABS, SLA to LF concordance 2004. 
Figure 5 Comparison of ABS Labour Force Region geography and Functional Zone Geography (Cluster 2). NSW

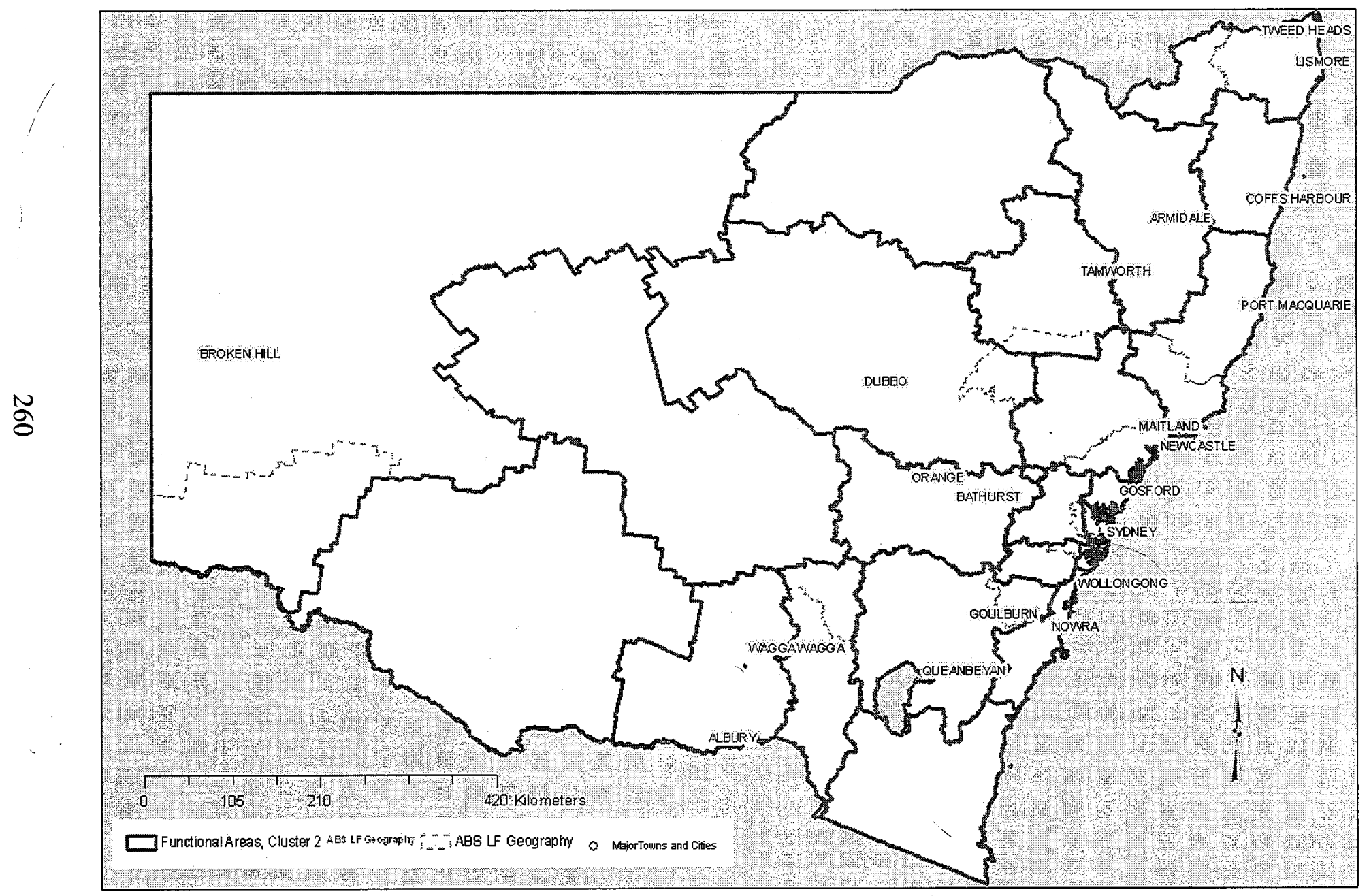



Source: ABS, JTW Custom Matrix, 2001 and ABS, SLA to LF concordance 2004. 
Figure 6 Comparison of ABS Labour Force Region geography and Functional Zone Geography (Cluster 2), Sydney Metropolitan Region

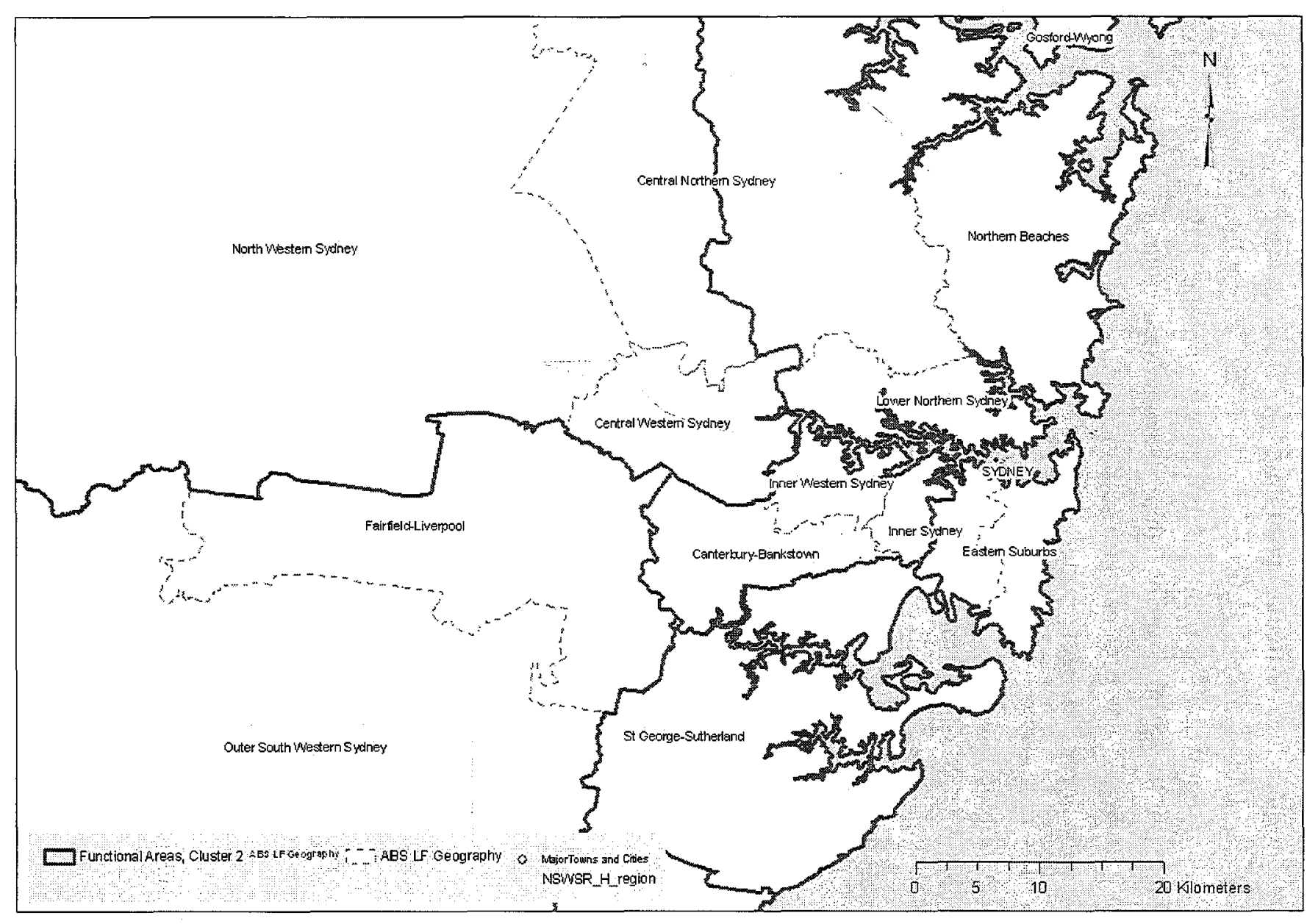

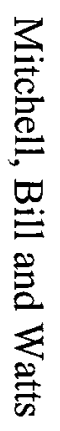

Source: ABS, JTW Custom Matrix, 2001 and ABS, SLA to LF concordance 2004. 


\section{Comparison of Labour Force estimates}

Table 4 uses 2001 Census of Population and Housing data to compare measures of unemployment, labour force participation and the ratio of part-time to full-time employment generated using the ABS LF region geography and the Functional Area geography. ${ }^{6}$ The results indicate that, on average, the design of the ABS LF region is such that these geographies tend to produce lower estimates of the unemployment rate and higher estimates of labour force participation when compared to the newly created functional areas. Measures of standard deviation in unemployment rates indicate that there is less dispersion between SLAs comprising a functional area compared to those SLAs in a labour force region. The intra-regional deviation in rates is 1.8 for the functional areas compared to 2.1 for the LF region geography, which suggests that unemployment rates within this new geography are much more alike, or homogeneous. While it is difficult to assert the primacy of one geography over another, the particular groupings of SLAs devised by the ABS for the dissemination of its labour force statistics are not as internally homogeneous as the Functional Area geography devised using the Intramax technique. ABS LF region geography is currently principally based on ensuring equal distribution of population and labour force ${ }^{7}$ (necessitated in part by the need to maintain statistical reliability in regional estimates from the national Labour Force Survey), rather than underlying economic activity, hence the proliferation of LF regions in metropolitan Sydney versus non-metropolitan NSW. The important point to note is that the MAUP problem may be resulting in tangible differences in measures of regional labour force outcomes. Keeping in mind the need to ensure statistical reliability in regional estimates, the particular delineation of spatial boundaries deserves serious consideration in the dissemination of Australian labour force statistics. 
Table 4 Comparison of ABS Geographies, Functional Area Geography and Labour Force Region Geography, 2001.

\begin{tabular}{|c|c|c|c|c|c|c|c|c|c|}
\hline Functional Area Geography & UR & LFP & $\begin{array}{l}\text { PT/FT } \\
\text { Emp. }\end{array}$ & $\begin{array}{l}\text { Standard } \\
\text { Deviation } \\
\text { (UR rate) }\end{array}$ & $\begin{array}{lll}\text { Labour } & \text { Force } & \text { Region } \\
\text { Geography } & & \\
\end{array}$ & UR & LFP & $\begin{array}{l}\text { PT/FT } \\
\text { Emp. }\end{array}$ & $\begin{array}{l}\text { Standard } \\
\text { Deviation } \\
\text { (UR rate) }\end{array}$ \\
\hline & $\%$ & $\%$ & $\%$ & & & $\%$ & $\%$ & $\%$ & \\
\hline Canterbury-Bankstown & 6.9 & 62.2 & 39.7 & 1.77 & Inner Sydney & 6.2 & 70.6 & 36.5 & 1.19 \\
\hline South Sydney, Inner Sydney & 5.5 & 68.5 & 39.8 & 1.27 & Eastern Suburbs & 4.8 & 67.7 & 42.6 & 0.90 \\
\hline $\begin{array}{l}\text { Hurtsville, Kogarah and Sutherland Shire } \\
\text { Lower Northern Sydney, Eastern Central }\end{array}$ & 4.5 & 65.8 & 44.9 & 1.26 & St George Sutherland & 4.5 & 65.8 & 44.9 & 1.26 \\
\hline $\begin{array}{l}\text { Northern Sydney and Northern Beaches } \\
\text { Hawkesbury. Blacktown. Blue Mountains }\end{array}$ & 3.7 & 68.0 & 46.7 & 0.45 & Canterbury-Bankstown & 8.4 & 56.8 & 40.7 & $\begin{array}{l}0.70 \\
3.11\end{array}$ \\
\hline $\begin{array}{l}\text { and Baulkham Hills } \\
\text { Fairfield-Liverpool and Outer South }\end{array}$ & 6.4 & 65.6 & 42.4 & 2.64 & Fairfield Liverpool & 10.6 & 59.1 & 37.1 & \\
\hline Western Sydney & 9.0 & 62.4 & 39.6 & 3.39 & Outer South Western Sydney & 7.0 & 67.4 & 43.0 & 2.29 \\
\hline Wollongong and Shoalhaven & 9.4 & 56.6 & 57.4 & 2.12 & Inner Western Sydney & 5.4 & 63.4 & 40.8 & 1.58 \\
\hline $\begin{array}{l}\text { Yass and Yarrowlumla } \\
\text { Goulburn }\end{array}$ & $\begin{array}{l}5.3 \\
8.4\end{array}$ & $\begin{array}{l}64.0 \\
58.0\end{array}$ & $\begin{array}{l}50.8 \\
64.7\end{array}$ & $\begin{array}{l}1.94 \\
3.78\end{array}$ & $\begin{array}{l}\text { Central Western Sydney } \\
\text { North Western Sydney }\end{array}$ & $\begin{array}{l}8.1 \\
6.5\end{array}$ & $\begin{array}{l}60.0 \\
66.7\end{array}$ & $\begin{array}{l}39.5 \\
43.0\end{array}$ & $\begin{array}{l}2.64 \\
2.14\end{array}$ \\
\hline Gosford-Wyong & 8.5 & 56.8 & 58.4 & 1.85 & Lower Northern Sydney & 3.9 & 68.8 & 39.1 & 0.54 \\
\hline $\begin{array}{l}\text { Newcastle and Port Macquarie } \\
\text { Great Lakes and Hastings }\end{array}$ & $\begin{array}{c}9.8 \\
12.7\end{array}$ & $\begin{array}{l}58.3 \\
48.6\end{array}$ & $\begin{array}{l}58.4 \\
70.0\end{array}$ & $\begin{array}{l}1.94 \\
3.69\end{array}$ & $\begin{array}{l}\text { Central Northern Sydney } \\
\text { Northern Beaches }\end{array}$ & $\begin{array}{l}3.6 \\
3.4\end{array}$ & $\begin{array}{l}68.2 \\
69.6\end{array}$ & $\begin{array}{l}50.6 \\
49.8\end{array}$ & $\begin{array}{l}0.39 \\
0.42\end{array}$ \\
\hline Coffs Harbour and Grafton & 13.5 & 52.9 & 71.7 & 2.36 & Gosford-Wyong & 8.5 & 56.8 & 58.4 & 1.85 \\
\hline Tamworth \& Surrounds & 8.9 & 60.2 & 50.1 & 2.35 & Newcastle Sector & 10.2 & 57.6 & 60.3 & 0.90 \\
\hline Armidale \& Surrounds & 8.9 & 58.5 & 54.3 & 2.02 & Hunter excluding Newcastle & 8.2 & 56.3 & 52.5 & 1.78 \\
\hline Narrabri, Moree Plains \& Surrounds & 9.3 & 64.0 & 44.8 & 2.25 & $\begin{array}{l}\text { Wollongong Statistical Region } \\
\text { Illawarra excluding }\end{array}$ & 9.0 & 58.7 & 54.8 & 1.92 \\
\hline Richmond-Tweed and Tenterfield & 12.4 & 53.3 & 69.8 & 1.73 & Wollongong & 8.8 & 53.0 & 65.7 & 3.53 \\
\hline Dubbo and Surrounds & 7.6 & 61.0 & 47.3 & 1.51 & $\begin{array}{l}\text { South Eastern } \\
\text { Richmond-Tweed and Mid- }\end{array}$ & 6.8 & 61.7 & 54.1 & 2.85 \\
\hline Lachlan, Forbes, Parkes and Colbar & 7.0 & 60.8 & 44.4 & 1.22 & $\begin{array}{l}\text { North Coast } \\
\text { Northern, Far West-North }\end{array}$ & 12.9 & 52.0 & 70.5 & 2.30 \\
\hline Orange, Lithgow \& Surrounds & 7.7 & 61.3 & 49.7 & 2.08 & Western and Central West & 8.3 & 60.5 & 49.0 & 2.30 \\
\hline Wentworth \& Central Dowling & 9.9 & 56.4 & 51.2 & 3.70 & Murray-Murrumbidgee & 6.3 & 63.7 & 46.6 & 1.74 \\
\hline Tumut, Gundagai \& Surrounds & 6.4 & 60.0 & 46.6 & 1.05 & & & & & \\
\hline Albury, Hume \& Surrounds & 7.2 & 63.5 & 49.5 & 1.60 & & & & & \\
\hline Murray-Murrumbidgee \& Surrounds & 4.9 & 64.9 & 42.4 & 1.59 & & & & & \\
\hline Standard Deviation & 2.5 & 4.8 & 9.6 & & Standard Deviation & 2.4 & 5.5 & 9.2 & \\
\hline Average (of regions) & 8.1 & 60.5 & 51.4 & 1.80 & Average (of regions) & 7.2 & 62.1 & 48.5 & 2.11 \\
\hline Average (in aggregate) & 7.2 & 62.2 & 47.6 & 3.36 & Average (in aggregate) & 7.2 & 62.2 & 47.6 & 3.36 \\
\hline
\end{tabular}




\section{Conclusion}

In exploring the best way to delineate regional labour markets such that the resulting geography has inherent 'economic meaning' we have developed regional demarcations (termed functional areas) based on a hierarchical aggregation technique known as Intramax. This technique is applied to Journey to Work data which explicitly captures the economic interactions of firms and workers across space. The technique, in all 3 stages of clustering, delivers very interesting results. It establishes a new geography representing the space over which supply (workers) and demand (firms) are seeking to interact as shown by the maximisation of commuting flows. It also helps us better understand the way regions are linked, illustrated by the hierarchy visible in the dendrograms. The latter application is particularly useful within metropolitan areas where labour market flows have previously been represented by sizeable matrices of data, difficult to order and comprehend. The hierarchical aggregation technique clearly indicates which regions connect via their labour market flows and the order in which they connect. This has obvious applications for planners and policy makers broadly interested in regional interactions (in terms of economic activity and housing), as well as those expressly interested in labour market problems.

The Intramax technique emphasises labour force flows and optimises SLA groupings based on higher than expected interactions between neighbouring regions, and appears to provide a much closer approximation of a local labour market. Mapping the 24 functional areas (cluster 2) provides an informative critique of current labour force geography. These functional areas generally collapse metropolitan and split non-metropolitan Labour Force regions (with the split often centred around a major regional town). This would suggest the need perhaps for the ABS to reassess its geography (keeping in mind requirements for statistical reliability in delivering regional estimates from a national survey). The functional area geography reduces intra-region dispersion in unemployment rates, which is to say that the geography tends to group regions that are more homogeneous. A simple application using 2001 Census data reveals that on average the emerging unemployment rates are higher and labour force participation rates are lower than standard LF regions, an indication that the MAUP problem may be resulting in observable differences. Given that ABS regional labour force estimates are widely used by policy makers and practitioners it is important that these findings are given due consideration.

Further work remains in applying this technique to the 2006 Census data to develop an updated geography. Exploring the occupation dimensions of these local labour markets (see Bill, Mitchell and Watts, 2007) may also be a useful future application of the method demonstrated here.

\section{References}

Barros, R., Broadbent, R.A., Cordey-Hayes, M., Massey, D.B., Robinson, K. And Willis, J. (1971) 'An operational urban development model for Cheshire', Environment and Planning, 3, 115-234.

Baum, S., O'Connor, K. and Stimson, R. (2005) Fault Lines Exposed: Advantage and Disadvantage across Australia's Settlement System, Monash University ePress, Clayton.

Berry, B.J.L. (1968) 'A synthesis of formal and functional regions using a general field theory of spatial behaviour', in B.J.L. Berry, D.F. Marble (eds.) Spatial Analysis, PrenticeHall, Englewood Cliffs, 419-428.

Berry, M. (2006) 'Housing Affordability and the Economy: A Review of Labour Market Impacts and Policy Issues', National Research Venture 3: Housing Affordability for Lower 
Income Australians, Research Paper 5, Australian Housing and Urban Research Institute, RMIT-NATSEM Research Centre, August 2006.

Bill, A., Mitchell, W. \& Watts, M. (2006) 'Examining the Relationship Between Commuting Patterns, Employment Growth and Unemployment in the NSW Greater Metropolitan Region', Australian Journal of Social Issues, 41(2), 233-245.

Bill, A., Mitchell, W.F. and Watts, M. (2007), 'The Occupational Dimensions of Local Labour Markets in Australian Cities', Centre of Full Employment and Equity (CofFEE), University of Newcastle, Australia.

Coombes, M.G., Green, A.E. and Openshaw, S. (1986) 'An Efficient Algorithm to Generate Official Statistical Reporting Areas', Journal of the Operational Research Society, 37(10), 943-53.

Coombes, M.G. (2000) 'Defining Locality Boundaries with Synthetic Data', Environment and Planning $A$, 32, 1499-1518.Goetgeluk, R. (2006) 'Dynamic clusters in migration patterns: Intramax-analyses of inter-municipal migration flows between 1990 and 2004', Paper presented at the ENHR conference Housing in an expanding Europe: theory, policy, participation and implementation, Slovenia, July.

Green, A. (1987) 'Alternative Approaches to Defining Local Labour Markets for Urban and Regional Policy' in Turok', I. (ed.) Travel to Work Areas and the Measurement of Unemployment, Conference Proceedins, Edinburgh.

Gregory, R.G. \& Hunter, B. (1995) 'The MacroEconomy and the Growth of Ghettos in Urban Poverty Australia', Discussion Paper No. 325, Economics Program Research School of Social Sciences, Australian

Hasluck, C. (1983) 'The Economic Analysis of Urban Labour Markets', Journal of Industrial Affairs, 10(2), 25-31.

Lawson, J. and Dwyer, J. (2002), 'Labour Market Adjustment in Regional Australia', Research Discussion Paper, 2002-04, Economic Group, Reserve Bank of Australia.

Masser, I. and Brown, P.J.B. (1975) 'Hierarchical aggregation procedures for interaction data', Environment and Planning A, 7, 509-523.

Masser, I. And Scheurwater, J. (1980) 'Functional regionalisation of spatial interaction data: an evaluation of some suggested strategies', Environment and Planning A, 12, 1357-1382.

Mitchell, W.F. and Carlson, E. (2005) 'Why Do Disparities in Employment Growth Across Metropolitan and Regional Space Occur?' Australasian Journal of Regional Studies, 11(1), $25-40$.

Mitchell, W.F. and Bill, A. (2006) 'Who benefits from Growth? Disadvantaged workers in growing regions', Australian Journal of Labour Economics, 9(2), 239-256.

O'Connor, K. and Healy, E. (2002) The Links Between Labour Markets and Housing Markets in Melbourne, Australian Housing and Urban Research Institute (AHURI), Swinburne-Monash Research Centre.

Openshaw, S. (1984) 'The modifiable areal unit problem', Concepts and Techniques in Modern Geography, 38(41).

Papps, K.L. and Newell, J.O. (2002) 'Identifying Functional Labour Market Areas in New Zealand: A Reconnaissance Study Using Travel-to-Work Data', IZA Discussion Paper 443. 
Slater, P.B. (1975) 'A hierarchical regionalisation of Russian administrative units using 19651969 migration data', Soviet Geography, 16, 453-465.

Trendle, B. (2004) 'The role of migration in regional labour market adjustment: the case of Queensland during the 1996-2001 intercensal period', Working Paper 27, Labour Market Research Unit, Department of Employment and Training, Queensland Government.

Watts, M.J. (2004) 'Local Labour Markets in New South Wales: Fact or Fiction?' in E. Carlson (ed.) A Future that Works - economics, employment and the environment, Proceedings of the 6th Path to Full Employment Conference, December.

Watts, M.J., Baum, S., Mitchell, W.F. and Bill, A. (2006) 'Identifying local labour markets and their spatial properties', Presented to the ARCRNSISS Annual Conference, Melbourne, May.

Yates, J., Randolph, B. and Holloway, D., (2006a), 'Housing Affordability, Occupation and Location in Australian Cities and Regions', Australian Housing and Urban Research Institute (AHURI), Melbourne.

Yates, J., Randolph, B., Holloway, D. and Murray, D. (2006b), Housing Affordability, Occupation and Location in Australian Cities and Regions, Final Report, Australian Housing and Urban Research Institute (AHURI), Melbourne.

Yates, J. (2005), 'Are Occupational Choices Affecting Housing Choices?', Paper prepared for the Australian Social Policy Conference, 2005, 'Looking'Back, Looking Forward - A Quarter of a Century of Social Change', University of New South Wales, 20-22 July 2005. 
Figure A1 Functional areas for NSW derived using the rules-based Coombes approach

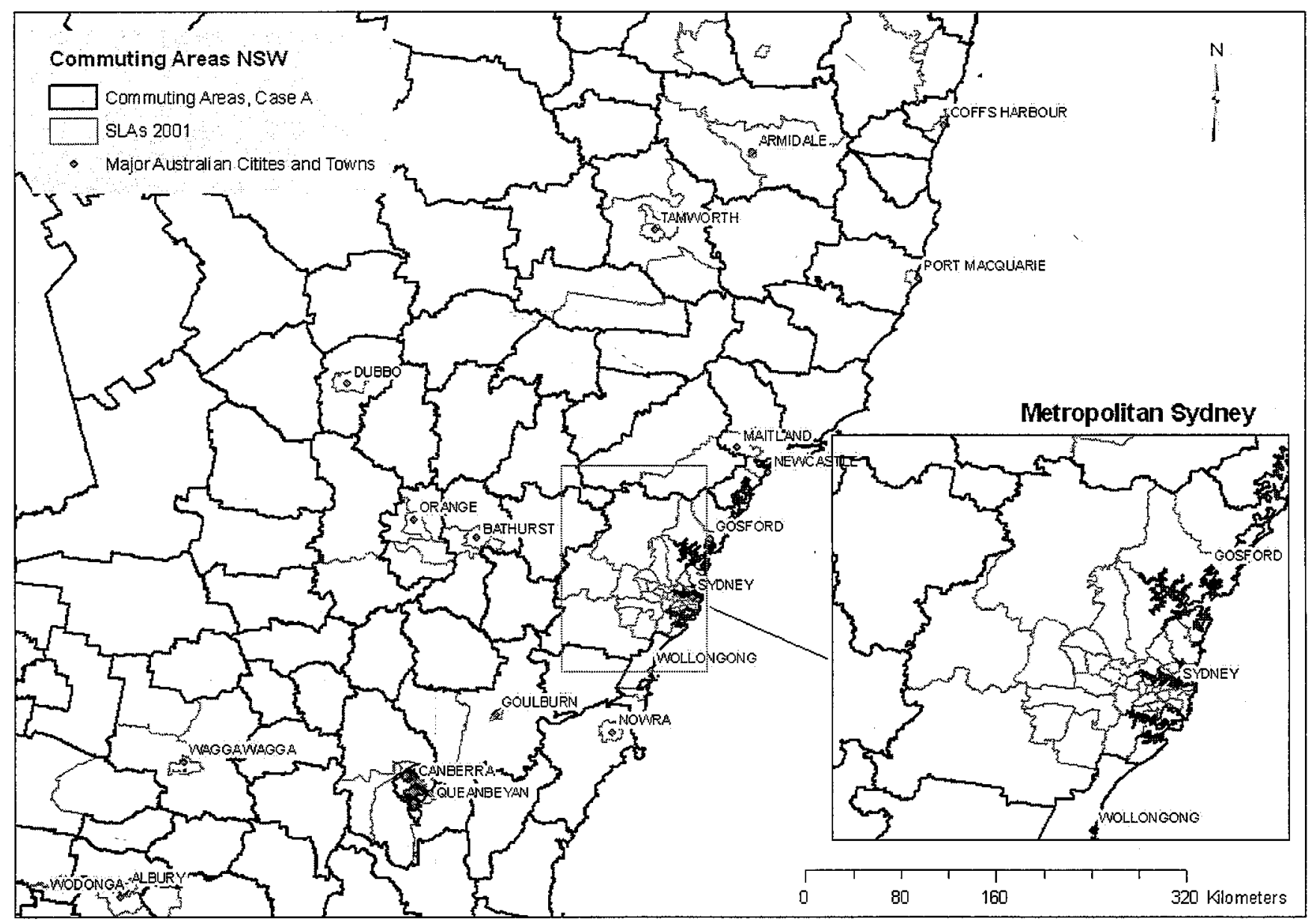

Source: Watts, M.J., Baum, S., Mitchell, W.F. and Bill, A. (2006) 
Figure A2 Dendrogram for NSW SLAs, 2001

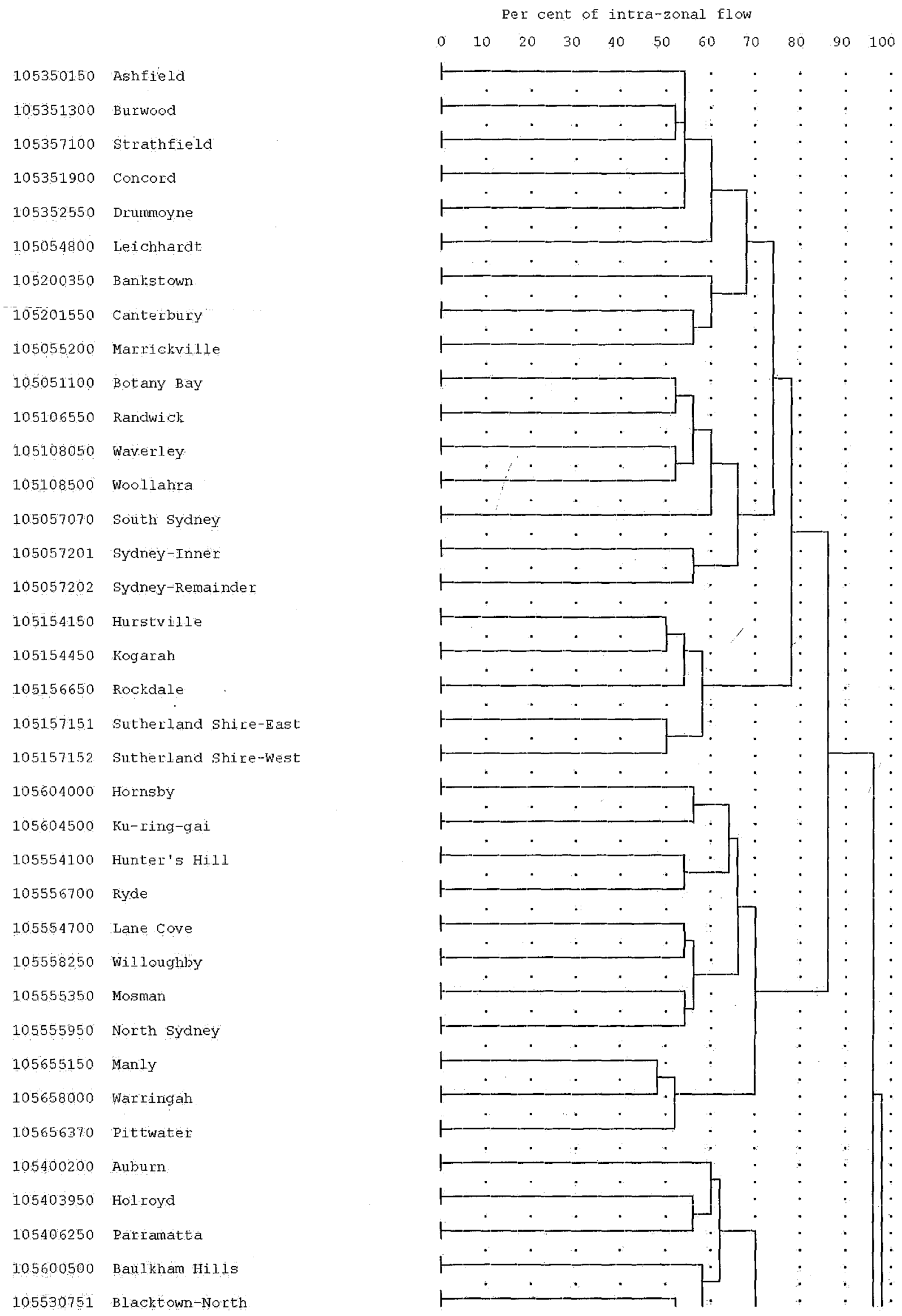




\begin{tabular}{|c|c|}
\hline 105530752 & Blacktown-South-East \\
\hline 105530753 & Blacktown-South-West \\
\hline 105456350 & Penrith \\
\hline 105450900 & Blue Mountains \\
\hline 105453800 & Hawkesbury \\
\hline 105301450 & Camclerı. \\
\hline 105308400 & Wollondilly \\
\hline 105301500 & Campbel1 town \\
\hline 105252850 & Fairfield \\
\hline 105254900 & Liverpool \\
\hline 115054400 & Kiama \\
\hline 115056900 & Shellharbour \\
\hline 115058450 & Woll longong \\
\hline 115076951 & shoalhaven-Pt A \\
\hline 115106952 & Shoalhaven-Pt $\mathrm{B}$ \\
\hline 115108350 & Wingecarribee \\
\hline 145101050 & Boorowa \\
\hline 145103600 & Gunning \\
\hline 145108700 & Yass \\
\hline 145056450 & queanbeyan \\
\hline 145058651 & Yarrowlumla-It A \\
\hline 145108652 & Yarrowlumla-Pt B \\
\hline 145107250 & Tallaganda \\
\hline 1.45102400 & Crookwell \\
\hline 145103150 & Goulburn \\
\hline 145105450 & Mulwaree \\
\hline 145150550 & Bega Valley \\
\hline 14.5152750 & Eurobodalla \\
\hline 145201000 & Bombala \\
\hline 145202050 & Cooma-Monaro \\
\hline 145207050 & Snowy kiver \\
\hline 105703100 & Gosford \\
\hline 105708550 & Wyong: \\
\hline 110051720 & Cessnock \\
\hline 110107000 & Singleton \\
\hline 110102700 & Dungog \\
\hline 110055050 & Maitland \\
\hline 110056400 & Port stephens \\
\hline
\end{tabular}

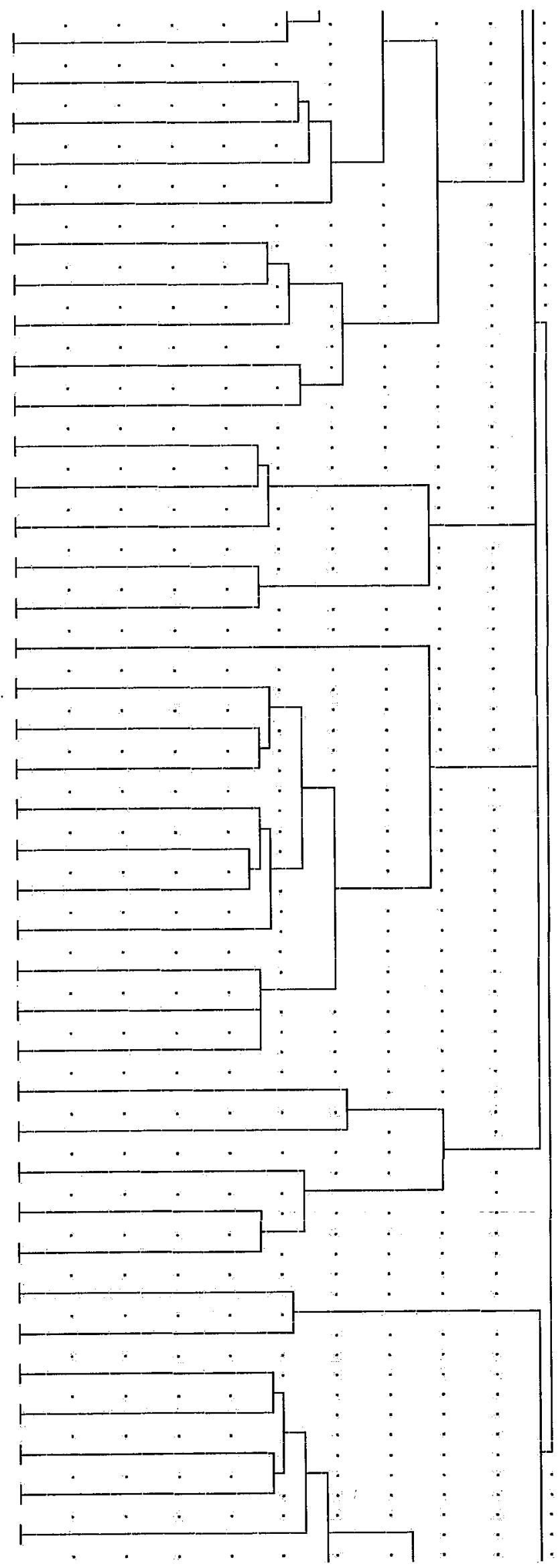



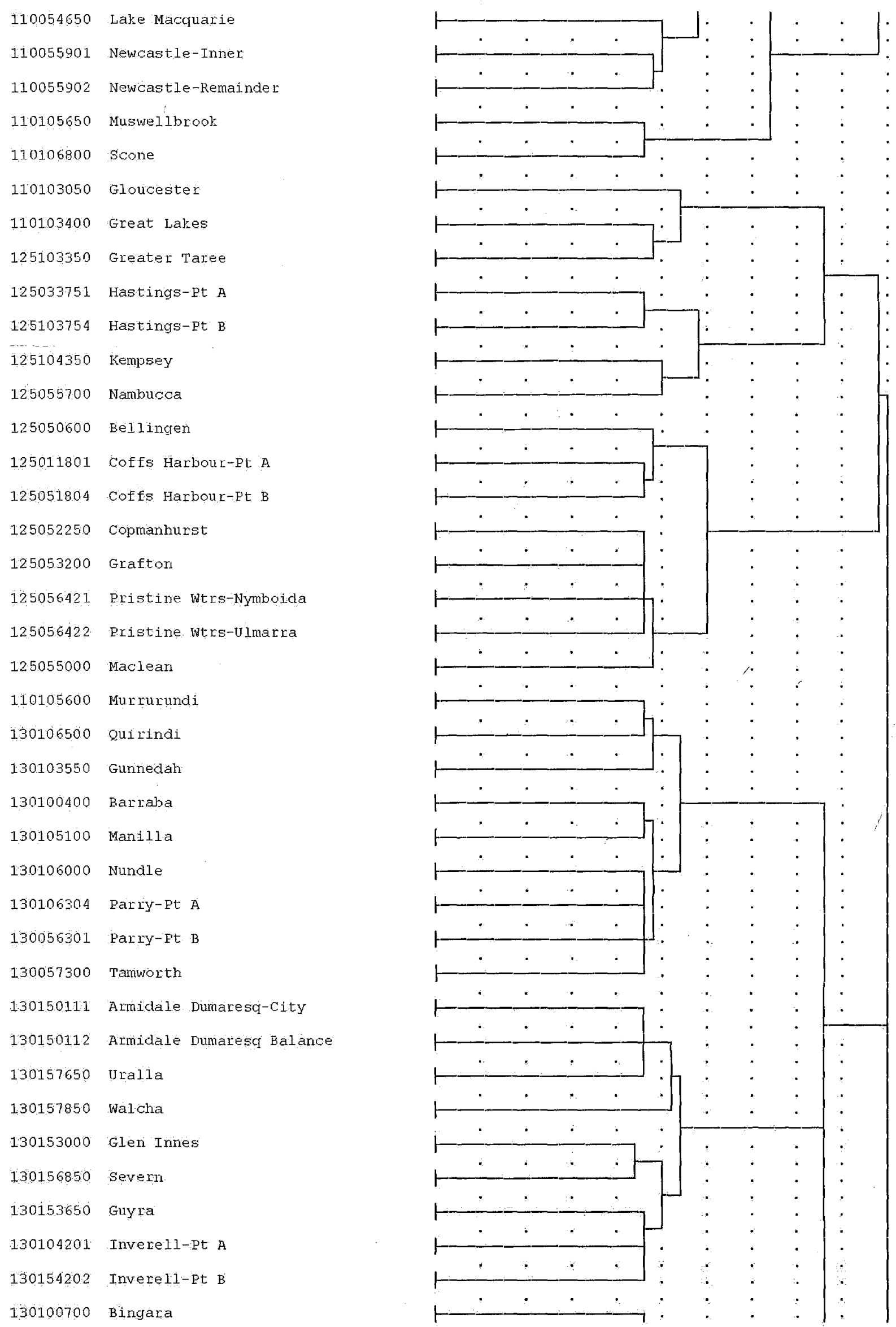


\begin{tabular}{|c|c|}
\hline 130108600 & Yallaroi \\
\hline 130205300 & Moree Plains \\
\hline 130205750 & Narrabri \\
\hline 135107900 & Walgett \\
\hline 120100250 & Ballina \\
\hline 120074851 & Lismore-Pt $A$ \\
\hline 120104854 & Lismore-Ft $\mathrm{B}$ \\
\hline 120101350 & Byron \\
\hline 120104550 & Kyogle \\
\hline 130157400 & Tenterfield \\
\hline 120106611 & Richmond Vailey-Casino \\
\hline 120106612 & Kichmond Valley Balance \\
\hline 120057551 & Tweed-Pt A \\
\hline 120107552 & Tweed-pt B \\
\hline 110105250 & Merriwa \\
\hline 135051950 & Coolah \\
\hline 135052100 & Coonabarabran \\
\hline 135102150 & Coonamble \\
\hline 135052950 & Gilgandra \\
\hline 135055400 & Mudgee \\
\hline 140106750 & Kylst́one \\
\hline 135100950 & Bogan \\
\hline 135107950 & warren \\
\hline 135055850 & Narromine \\
\hline 135012601 & Dubbo-Pt $A$ \\
\hline 135052604 & Dubbo-Pt. B \\
\hline 135058150 & Wellington \\
\hline 135151750 & cobar \\
\hline 140154600 & Lachlan \\
\hline 140150800 & Bland \\
\hline 140158100 & Weddin \\
\hline 140152900 & Forbes \\
\hline 1.140156200 & Parkes \\
\hline 140050450 & Bathurst \\
\hline 140052801 & Evans-Pt A \\
\hline 140102802 & Evans-Pt: B \\
\hline 140106100 & oberon \\
\hline 40103300 & Greater Lithgow \\
\hline
\end{tabular}

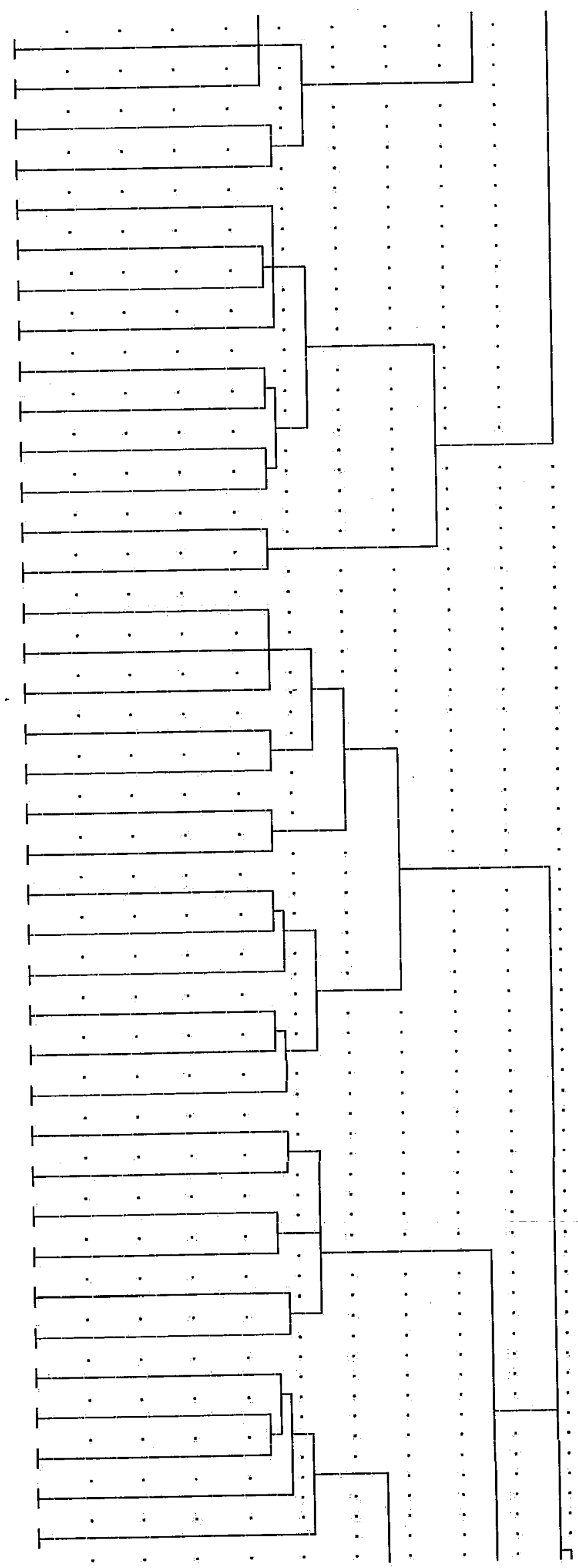




\begin{tabular}{|c|c|}
\hline 140050851 & Blayney-Pt A \\
\hline 140100852 & Blayney-Dt B \\
\hline 140051401 & Cabonne-Pt A \\
\hline 140056150 & Orange \\
\hline 140101402 & Cabonne-Pt B \\
\hline 140151403 & Cabonne-Pt c \\
\hline 140152350 & Cowra \\
\hline 135151150 & Bourke \\
\hline 135151200 & Brewarrina \\
\hline 160101250 & Broken Hill. \\
\hline 160108809 & Unincorp. Far west \\
\hline 160101700 & Central Darling \\
\hline 155208200 & wentworth \\
\hline 145103700 & Harden \\
\hline 145108750 & Young \\
\hline 150102200 & Cootamundra \\
\hline 150103500 & Gundagai. \\
\hline 150107500 & Turnut \\
\hline 155107450 & Tumbarumba \\
\hline 150102000 & Coolamon \\
\hline 150104300 & Junee \\
\hline 150107350 & Temora \\
\hline 150057751 & Wagga hagga-It A \\
\hline 150107754 & Wagga Wagga-Pt B \\
\hline 150104950 & Lockhart \\
\hline 155107700 & Urana \\
\hline 155102450 & Culcairn \\
\hline 155103900 & Holbrook \\
\hline 155050050 & Albury \\
\hline 155054050 & Hume \\
\hline 155102300 & Corowa \\
\hline 150151600 & Carrathool \\
\hline 150153850 & Hay \\
\hline 150153450 & Griffith \\
\hline 150154750 & Leeton \\
\hline 150105800 & Narrandera \\
\hline 150155550 & Murrumbidgee \\
\hline 155154250 & Jerilderie \\
\hline 155150650 & Berrigan \\
\hline
\end{tabular}

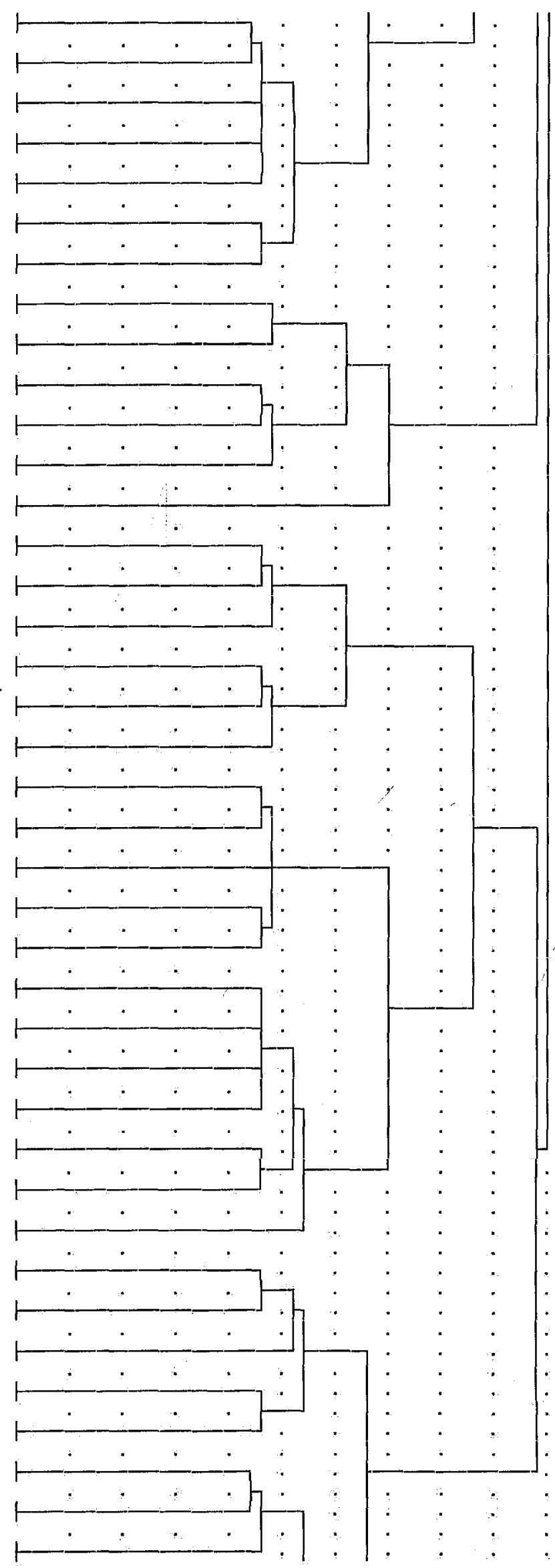




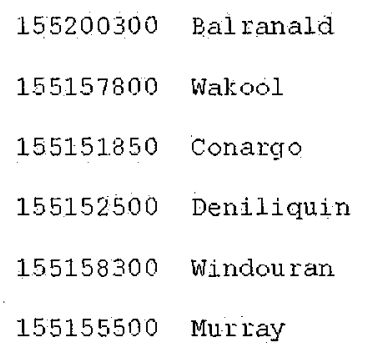

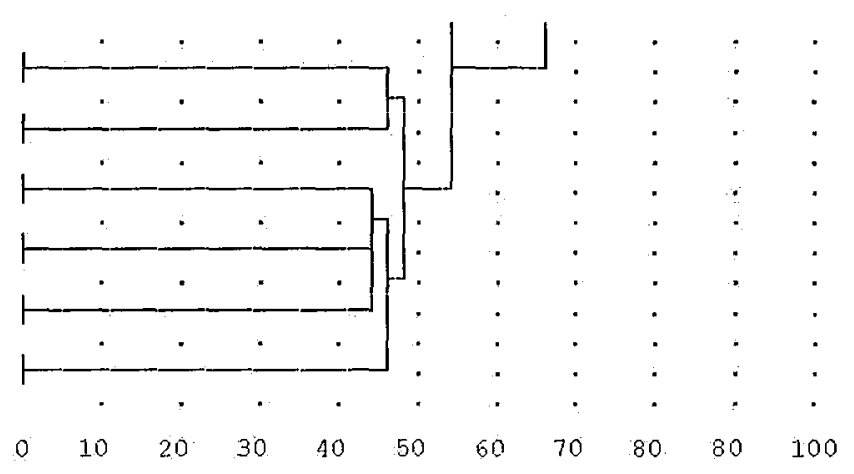

\footnotetext{
${ }^{1}$ The authors in order are Professor of Economics and Director of Centre of Full Employment and Equity, University of Newcastle, Australia (Mitchell), Research Fellow, Centre of Full Employment and Equity, University of Newcastle (Bill) and Associate Professor and Research Associate, Centre of Full Employment and Equity, University of Newcastle (Watts).
}

${ }^{2}$ Subsequent analysis reveals that a different parameterisation of the rules based Coombes algorithm can yield more spatially disaggregated commuting areas in the Sydney Metropolitan Area. The authors will publish a comparative analysis of these two techniques in due course.

${ }^{3}$ Watts (2004) developed a regional demarcation for NSW based on the Coombes et al algorithm (Coombes, 1986), but cross-border commuting was ignored and the adjustment of small flows to zero was not undertaken. It is considered that these nuances in the dataset used do not explain the differences in the regionalisations produced.

4 The intramax estimation was performed using the Flowmap software available from http://flowmap.geog.uu.nl. We also thank Tom de Jong who gave excellent software support.

${ }^{5}$ The LF geography illustrated in the above maps is based on an SLA to LF region concordance provided by the ABS, for 2004

see: http://www.ausstats.abs.gov.au/ausstats/subscriber.nsf/0/AE3E261E3BA2506ECA257139007746CE/\$File/6105 0_sla $\% 20$ to $\% 201$ ss $\% 20$ region $\% 20$ concordance jul2004.xls.

${ }^{6}$ Labour force measures are drawn from the ABS Census 2001 as it corresponds to the Journey-to-Work matrix used to construct the Functional Areas, and it is sufficiently spatially disaggregated.

${ }^{7}$ The ABS (2004) notes that "LFS regions were originally established after extensive consultation with major users of labour force data. Estimates for these LFS regions were first released in 1985. Factors in the design of the LFS regions included: the sample sizes required to yield reliable estimates; the need for consistency with the ASGC; and the need for comparability with other statistical collections. LFS regions are determined, in part, by the expected sample size for each region. If the regions are too small, then the accuracy of estimates will not be acceptable: relative standard errors on estimates will be very large, and the estimates will not be reliable or useful. The regions represent a compromise between user interest in small area data and the design limits of the sample".

See: http://www.abs.gov.au/AUSSTATS/abs@.nsf/94713ad445ff1425ca25682000192af2/44a9700b59346b98ca256f 5600768aac!OpenDocument 